\title{
CROWD LOGISTICS: HOUSEHOLD AS A LOGISTICS SERVICE PROVIDER
}

\author{
Snežana Tadić ${ }^{1}$, Miloš Veljović ${ }^{2}$, Slobodan Zečević ${ }^{3}$ \\ ${ }_{1,2,3}$ University of Belgrade, Faculty of Transport and Traffic Engineering, Vojvode Stepe 305, \\ 11000 Belgrade, Serbia
}

Received 15 June 2021; accepted 4 November 2021

\begin{abstract}
The number and spatial dispersion of households and their resources (means of transport, storage space, human resources, etc.), a large number of daily trips of various motives (shopping, work, school, tourism, waste disposal, etc.), makes households important participants in logistics chains. Moreover, these features make them potentially very important providers of logistics services of delivery, storage, waste collection, etc., both for other households and for companies. The use of logistics services, resources of households, i.e. individuals, known as crowd logistics, is experiencing rapid development with the advent of numerous networks and applications, through which users connect with each other and get the opportunity to state and accept requests for logistics tasks. In this paper, the role of households in the performance of logistics demands of other households and companies is analyzed and the basic crowd logistics services are structured, with special reference to the services in the last mile of the supply chain. Also, the basic benefits were identified, as well as the disadvantages, problems and challenges in the application of this concept.
\end{abstract}

Keywords: crowd logistics, household, logistics service, crowd delivery, crowd storage, crowd waste collection, last mile.

\section{Introduction}

It has long been possible to hire professional logistics service providers for performing logistics tasks. However, different processes and trends (growth of prices of logistics services and storage space, growth of mobility and number of people who own vehicles, development of information and communication technologies, Internet and mobile applications, growth of production and consumption of various goods and services, globalization, networking, growth social inequalities and poverty, etc.), as well as the demands and imperatives of modern times (development of efficient, sustainable, environmentally friendly logistics, reducing flows and better utilization of capacity, etc.) encourage individuals and companies to increasingly use the logistics services of ordinary people. This practice is called crowd logistics. Users and providers of crowd logistics services publish, i.e. accept requests for the execution of logistics tasks through information and communication platforms, mobile applications or social networks. The performance of crowd services usually has a commercial, for-profit character, so crowd workers usually receive money or other type of economic benefit for the performed task (e.g. discount when buying the shipper's goods). Crowd workers most often use the

\footnotetext{
${ }^{1}$ Corresponding author: s.tadic@sf.bg.ac.rs
} 
resources of their households to carry out these tasks. Therefore, it can be said that these households have the role of a kind of logistics service providers.

Given the number and territorial dispersion, households are significant and ubiquitous logistics systems, generators of logistics flows, participants in various categories of logistics chains and potential providers of logistics services. Nevertheless, households have very rarely been the subject of research in this context (Tadić \& Veljović, 2020a, $2020 b, 2020 \mathrm{c}$ ). On the other hand, the crowd logistics concept attracts a lot of attention from researchers. Carbone et al. (2017) proposed the conceptualization of crowd logistics and analyzed the types of services within this concept. A significant contribution to the theoretical foundation, the study of the potential and challenges of crowd logistics in the management of goods and information was made by Mladenow et al. (2015; 2016) and Frehe et al. (2017). RześnyCieplińska and Szmelter-Jarosz (2019) analyzed crowd logistics solutions from the perspective of different stakeholders. Rai et al. (2017) explored crowd logistics as a chance to achieve the sustainability of urban freight transport.

This paper will analyze the role of households in performing logistics flows of other households and companies and will perform structuring and analysis of basic crowd logistics services, with special emphasis on services in the last mile of the supply chain, which is the main goal and contribution of paper. Unlike previous research, the paper analyzes waste collection by households as a crowd logistics service and explores the potential for its development and application.
Also, the paper identifies the basic benefits, as well as disadvantages, problems and challenges in the application of the crowd logistics concept. In this context, the paper is a contribution to a stronger and more comprehensive theoretical foundation of this, still young field of logistics.

\section{The Concept, Development and Benefits of Crowd Logistics}

Various crowdsourcing initiatives have been developed in recent decades. The term crowdsourcing was created from the words crowd and outsourcing, it popularized by Howe (2006) and implies that the activities usually performed by companies are entrusted to ordinary people, i.e. "crowd" of individuals (Carbone et al., 2017). Individuals or companies can use financial (crowd funding), intellectual (crowd innovation), but also logistical resources and services of individuals, i.e. their households (crowd logistics) (Carbone et al., 2017).

Various forms of cooperation and mutual assistance in logistics tasks, which households have been practicing since ancient times, can be considered a precursor to the crowd logistics concept. Thus, in rural areas far from shopping centers in the past, but even today, it is often the case that the purchase and delivery of goods for several households is done by one resident. In the same way, a tenant of a residential building in an urban area can deliver goods for his own and neighboring households. Also, drivers or users of public city, intercity or international road, railway and other modes of transport performed but still perform the delivery of packages, documents, money, etc., for friends, relatives, acquaintances, etc. during 
the performance of their own flows. Storing goods, materials or freights with neighbors, friends or relatives, due to the lack of storage space in one's own household, is also one of the examples of using the resources of other households. Finally, the collection and removal of waste/secondary raw materials from the household can also be performed by another household, which is an alternative to professional services of this kind.

Also, companies used household logistics services. Households, hired by companies, acted as collection and delivery points (CDPs) for purchasers from a residential building, street, or neighborhood (e.g., the Organic 2000 project, see Cairns, 1996). In addition to receiving and storing goods, households also made deliveries to addresses of customers (usually friends and neighbors), thus taking on the role of local agents, i.e. drop off companies. This concept has been applied in the past by mail order companies
(McKinnon \& Tallam, 2003). Companies can also hire households to collect and dispose of waste.

The innovation of the modern crowd logistics concept, which has been developing since the beginning of the 21st century, in relation to such practices are information and communication technologies and social networks, which enable more efficient communication and contracting of logistics operations. Moreover, they enable the networking of all users who seek or offer logistics services in a wider geographical area and who do not have to know each other. The application of crowd logistics can bring numerous economic, environmental and social benefits (Fig. 1). Therefore, this concept can be very important for the sustainable development of logistics and should be taken into account when planning the logistics systems of households, companies and entire areas.

\begin{tabular}{|c|c|c|c|}
\hline & \multicolumn{2}{|c|}{ Benefits of crowd logistics implementation } & \\
\hline Economic & Environmental & & Social \\
\hline $\begin{array}{l}\checkmark \text { Lower logistics costs (costs of } \\
\text { delivery, storage, fleet } \\
\text { maintenance, etc.) } \\
\checkmark \text { Less investment in fleet and CDPs } \\
\checkmark \text { Possibility of employment and } \\
\text { earnings } \\
\checkmark \text { Lower price of logistics services }\end{array}$ & $\begin{array}{l}\checkmark \text { Reducing flows, harmful } \\
\text { emissions, noise, vibration, etc. } \\
\checkmark \text { Reducing the construction of } \\
\text { warehouses, less occupying urban } \\
\text { green space and endangering } \\
\text { ecosystems } \\
\checkmark \text { More efficient waste management }\end{array}$ & & $\begin{array}{l}\text { Service for persons with reduced } \\
\text { mobility } \\
\text { Active social function of the elderly } \\
\text { Positive effects on the health and } \\
\text { mood of the population } \\
\text { Increasing social cohesion } \\
\text { Revitalization of rural areas }\end{array}$ \\
\hline
\end{tabular}

Fig. 1.

Benefits of Crowd Logistics Implementation

\section{Household as a Logistics System and Generator of Logistics Flows}

The household is a specific logistics system, which functions in accordance with the needs and desires of its members. Like other logistics systems, it consists of subsystems of ordering, packaging, transport, warehousing and inventory management. Ordering goods and services for the household is performed in the traditional way, in retail, catering, service and other facilities, but also remotely (by 
phone, mail, more and more via the Internet). Packaging and transport operations largely depend on the ordering system. Namely, the customer usually packs and delivers (on foot, by public transport, own passenger car) to the household the goods he ordered personally, while the goods ordered remotely are usually delivered to his home address by shipper, that is responsible for organizing the packaging and transport. However, it is also possible for the customer to buy goods at the point of sale, which is then delivered to his home address (e.g. furniture and white goods), just as the customer can deliver the goods ordered online himself. There are different storage systems in the household from the aspect of conditions and equipment, and they depend primarily on the type of goods and functions that the household performs (housing, agricultural, handicraft production, agritourism and hospitality, etc.). Household storage can be performed without special conditions and equipment or in special conditions with appropriate equipment in terms of temperature (refrigerators, freezers, etc.), humidity, light and other harmful external influences (pantries, shelves, drawers, cabinets), position of goods (holders for clothes or shoes), security (safes, cash registers, etc.), etc. One of the most important subsystems of household logistics is inventory management, primarily having in mind the importance of inventory management of food and other goods necessary for the life of household members and its maintenance, but also the capital captured by their holding and the risk of loss due to expiration.

Also, the household is a significant generator of logistics flows and a participant in various categories of logistics chains. There are input (independent procurement flows, home delivery, etc.), internal (e.g. flows between orchards, vegetable gardens, pastures or forests owned by a rural household) and output flows of household (flows of waste, returnable packaging, goods produced by household for sale, etc.) (Tadić \& Veljović, 2020a). Also, households generate numerous passenger flows (travel to work, school, doctor, theater, tourist tours, etc.). In performing flows, the capacities of the household logistics subsystems are very often not fully used.

Household transport capacities in the performance of usual flows, especially passenger, can be used for deliveries of goods, materials or freights or waste collection required by users, if they are performed in the same direction. Also, household space, equipment and staff can be used for storage, transshipment, enlargement, packaging of goods, etc. Therefore, households appear as potentially very important providers of crowd logistics services, both for other households, i.e. individuals, and for companies. The household may provide some of the services usually provided by logistics service providers (delivery, storage, transshipment, waste collection, etc.), but household services are not professional.

\section{Household Crowd Logistics Services}

The household can have the role of goods shipper and recipient, but also the executor of logistics operations for its own and the needs of other households and companies. The household/crowd worker can provide delivery, storage, a combination of these services, the service of waste collection. These services will be analyzed in more detail below.

Crowd delivery service involves the delivery of goods performed by a crowd worker, most 
often by his own van, car, scooter, bicycle, public transport or on foot (Carbone et al., 2017). Although delivery can be made even after the customer or crowd worker buys goods in retail facility (Ghajargar et al., 2016), this service is especially important in the context of e-commerce development, online ordering and home delivery. Namely, given that customers are increasingly buying goods online, it is necessary to develop efficient and sustainable (economically, environmentally and socially justified) models of goods distribution to consumers. The goods can be delivered by individuals who perform different flows every day (shopping tours, business trips, school, tourist tours, etc.). In doing so, the crowd worker can perform the complete delivery in the last mile from the shipper to the customer, its initial (from the shipper to the crowd worker household) or final part (last yard, from the crowd worker household or CDP to the customer home address). The delivery fee can be in cash or in the form of a discount provided by the shipper (Hübner et al., 2016). Crowd delivery has a number of advantages. First of all, it enables better use of transport capacities, encouraging consolidation and coordination of existing flows, potentially reducing the number of vehicle starts, congestion and harmful gas emissions (Sampaio et al., 2019). Also, some of the advantages of crowd delivery are (Tadić \& Veljović, 2021): number and territorial dispersion of potential crowd workers and flows that they perform every day, increasing delivery speed and flexibility, reducing operating costs and eliminating the cost of investing in fleet, reducing the number of unsuccessful delivery, efficiency in conditions of fluctuating demand on a daily and long-term level, efficiency of communication channels, etc.
A household may provide a long-term or temporary storage service for goods, materials or freights. Basements, spare rooms, garages or yards are most often used for the performance of this service (Carbone et al., 2017). Crowd storage services are gaining in importance, especially in urban areas. Land and real estate prices are high in these areas, so the space intended for logistics activities is slowly disappearing from cities (Tadić \& Zečević, 2016). Since households usually do not have a large storage space, they often buy a storage service for goods, most often seasonal (e.g. summer and winter equipment, seasonal clothing, holiday decorations) and other occasionally used goods (e.g. festive furniture) within the logistics centers (Subedi, 2018), but also within households, which provide storage services. Households can also be places of delivery and temporary storage of goods until the moment when the customer takes over. Finally, temporary goods storage and transshipment in household can be performed in the consolidation and deconsolidation of flows in the distribution work of companies (Tadić \& Veljović, 2020a).

Another service that a household can provide to other households or companies is crowd waste collection. This service will be described in more detail in section 4.3.

\subsection{Crowd Logistics Services in B2C and C2C Flows}

Crowd logistics services are especially important for performing the last mile of the supply chain, i.e. home delivery within the B2C (business to consumer) and C2C (consumer to consumer) business models. It is important to note that the abbreviations B2C, C2C and B2B (business to business) are used in this paper not only in the context 
of online business, but also other business models that involve cooperation between the categories of participants named in them (companies and consumers). Household logistics resources are suitable for home delivery operations, since the quantity and volume of goods in such deliveries are usually small (Visser et al., 2014). Home delivery is the direct or indirect delivery of goods to the customer's address, which is partially or fully performed by the retailer, manufacturer or third party (logistics service provider, courier, express or parcel service, postal operator, crowd worker) (Tadić \& Veljović, $2020 d)$. In addition to the customer's home address, the goods can be delivered to other locations, such as CDPs or drop off companies. CDPs are a network of locations where suppliers/operators pool and deliver ordered goods, and customers consignees pay, collect or return goods (Yuen et al., 2018; Piplani \& Sarasvat, 2012). The role of CDPs can be played by purpose-built facilities, existing commercial (trade, catering, etc.) facilities, but also by households. Drop off companies are an extension of the concept of CDPs and, in addition to receipt, also perform the final delivery to the customer address. The household can also perform the function of a drop off company.

a)

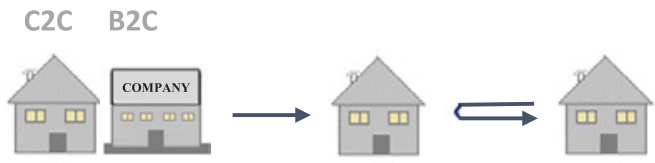

b)

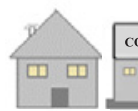

c)
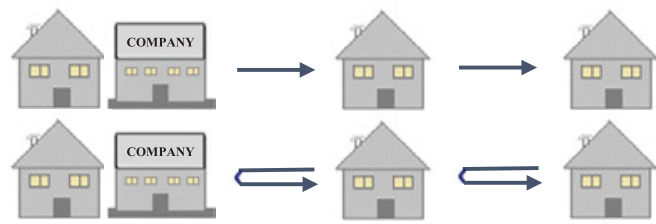

d)
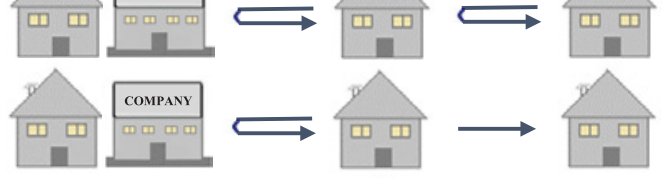

e)
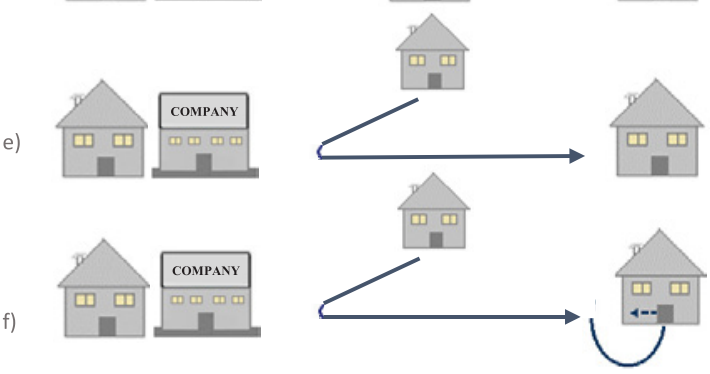

Fig. 2.

Household Services in Last Mile of C2C and B2C Flows

In the last mile of $\mathrm{B} 2 \mathrm{C}$ or C2C flows, households can provide services (Fig. 2):

a) Storage - the crowd worker receives and stores goods in his household until the moment when the customer takes over; the household has the role of CDP;

b) Storage and delivery - the crowd worker receives, stores goods in his household 
and delivers them to the customer; the household has the role of drop off company;

c) Pick-up and storage - the crowd worker picks up the goods at the shipper's location, delivers them to own household and stores them until the moment when the customer takes them over;

d) Pick-up, storage and delivery - the crowd worker takes over the goods at the shipper's location, delivers them to own household, stores them and delivers them to the customer;

e) Pick-up and delivery - the crowd worker takes over the goods at the shipper's location and delivers them to the customer;

f) Pick-up and unattended delivery - the crowd worker takes over the goods at the shipper's location and delivers them to the customer without his presence (e.g. access to the facility).
Except in the whole last mile and its initial segment, the household can perform crowd services in the final delivery segment in the last mile - the last yard. In this case, the shipper delivers the goods to CDPs (purpose-built, CDPs within commercial facilities or households that are not owned by the crowd worker), and the crowd worker provides services (Fig. 3):

a) Pick-up and delivery - the crowd worker takes over the goods in the CDP and delivers them to customer address;

b) Pick-up and storage - the crowd worker takes over the goods in the CDP and stores them in own household until the moment when the customer takes them over;

c) Pick-up, storage and delivery - the crowd worker takes over the goods in CDP, stores them in own household and delivers them to customer address. a)
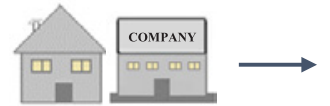

b)
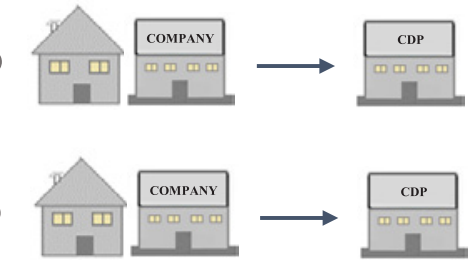

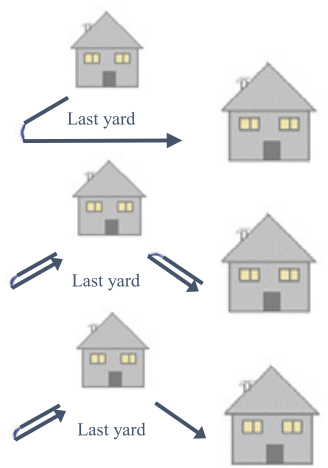

Fig. 3.

Household Services in the Last Yard of C2C and B2C Flows

For the performing mentioned services in the last mile or the last yard, the household can be hired by other households, i.e. customers, or by companies. Publishing and accepting requests for services can be performed through crowd-logistics mobile applications and social networks. Lately, more and more companies are involving households in the performing logistics tasks. Thus, Walmart, DHL and Amazon engage their customers in operations of delivering goods to other customers (Arslan et al., 2018). 
Households can also perform the return of delivered goods. In this case, the household can provide the previously described services, but in the opposite direction (collection of goods from the household, storage and delivery to the company or CDP). Given the complexity of the organization of return flows in home delivery (Tadić \& Veljović, 2020e), crowd services can play a significant role in this area, especially in reducing the number of flows and their negative effects (Sampaio et al., 2019).

It is important to note that the last mile, and especially the last yard, very often represents very short distances, which in some cases can be crossed on foot in a short time. However, even in such cases, crowd services can be of great importance, especially for people who have difficulty mobility: the elderly, the sick, the disabled, etc. On the other hand, elderly, whose physical health and free time enable them to participate in logistics operations, represent a significant potential for this area of logistics (Sampaio et al., 2019). In both cases, there are both economic (lower price than in the case of professional service, the possibility of earning money for crowd workers) and significant social benefits (assistance to vulnerable social groups, more active social function of the elderly).

\subsection{Crowd Logistics Services in B2B Flows}

Apart from the relations between companies and customers, households can also participate in performing flows between and within companies: trade, production, logistics, etc. (B2B). The household can provide identical services as in the last mile of C2C and B2C flows (Fig. 2), the only difference being that the recipients are not individuals/households, but companies. It is especially important to use household resources in the distribution work of companies, to perform transshipment, consolidation and deconsolidation of flows and temporary storage with monetary compensation to the household owner (analogous to the service shown in Fig. 2a in C2C and B2C flows) (Tadić \& Veljović, 2020a). After these activities, the goods are shipped to their final destinations according to the distribution plan. In this case, the household has the role of a hub in the distribution network of companies.

\subsection{Crowd Waste Collection Service}

Although in previous research, the service of collecting waste from households or companies, which is performed by another household, has not been identified as a crowd service, it can be categorized as such, considering the characteristics. Namely, the role of waste collectors (usually secondary raw materials) is very often played by households. These are individuals or families who usually visit households and companies in a certain area with light trucks and vans, collecting waste, i.e. goods, materials or freights that can be used in some way (reuse, recycling, etc.) or that needs to be handed over to the competent services (landfills, waste incineration services, etc.). After collection, the crowd worker can directly deliver the waste to the competent services (Fig. 4a), can perform its packaging, consolidation and storage until the moment when the competent services collect it (Fig. 4b) or deliver it to them independently (Fig. 4c). 
a)
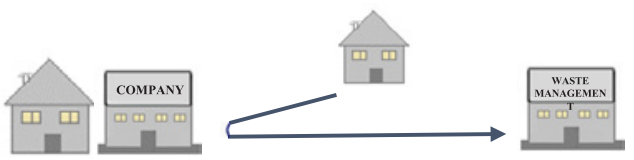

b)
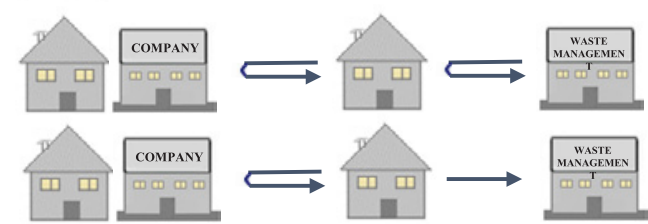

Fig. 4.

Crowd Waste Collection Service

The innovation of the crowd waste collection concept in relation to this service is in the way of communication between crowd workers and users. Informing users is still most often performed during the process of waste collection through loudspeakers. With the development of this concept as a crowd service, communication between service providers and users could be performed through modern information and communication technologies, mobile applications and networks. This could achieve better coordination of supply and demand for waste collection services, significant economic and environmental benefits.

\section{Disadvantages, Problems and Challenges in the Application of Crowd Logistics Concept}

Although examples of successful application of the crowd logistics concept are becoming more numerous, there are a number of disadvantages, problems and challenges in its application. This primarily refers to: reliability, security and privacy, distribution of responsibilities, legal restrictions, generation of flows, insufficient number of crowd workers, etc.
The main challenges relate to reliability, security and privacy. Executors of crowd logistics tasks are usually anonymous, so their behavior is unpredictable (Mladenow et al., 2016), which leads to unreliability, risk of theft or damage to goods, theft in the customer's household, endangering privacy, etc. Therefore, a transparent system and mechanisms for building trust between crowd workers and users should be created (Rai et al., 2017), a feedback system, personal websites of crowd workers and users, a secure messaging system, a secure online payment system and insurance should be introduced (Rougès \& Montreuil, 2014), stricter verification of worker identification and real-time shipment tracking (Wang et al. 2016). Also, these problems can be solved by hiring well-known crowd workers (relative, friend, associate, neighbor, etc.) (Devari et al., 2017).

Another challenge is the distribution of responsibilities. When damage to goods occurs during delivery, there is a dilemma as to who is responsible, the shipper or the crowd worker. Shipment insurance is still not a completely adequate solution to this problem, because in the legal sense it is often defined ambiguously (Mladenow et al., 2016). 
Also, it is necessary to solve the legal status of crowd workers, as well as the limitations, problems and obstacles in the application of crowd logistics. In many countries, there are still dilemmas in how to legally recognize crowd logistics services, as well as in understanding the rights and obligations of crowd workers. Thus, in some countries, crowd workers do not have to pay taxes for the services they provide, which cause dissatisfaction of professional logistics providers to whom paying taxes is an obligation. On the other hand, the question of the profitability of crowd services arises after the eventual introduction of taxes. Finally, in the existing legal framework of many countries, the work of crowd workers is a violation of laws and regulations (Frehe et al., 2017). Therefore, in the future, significant attention must be paid to the legal aspect of the application of crowd logistics.

One of the key success factors in the application of the concept is the existence of a critical mass of participants in the crowd logistics network (Agatz et al., 2012; Klumpp, 2017; Sampaio et al., 2019). As interest in crowd logistics in many areas, especially rural, is still small, the number of crowd workers in these areas is insufficient for the successful implementation of the concept. A critical mass of crowd workers can be achieved through effective marketing (Rougès \& Montreuil, 2014), i.e. instruments such as internet advertising, social networks and bonus programs (Mehmann et al., 2015; Rai et al., 2017).

Finally, although the basic potential of crowd logistics is existing flows and unused capacities, numerous crowd logistics initiatives, such as UberRUSH and Lalamove, involve generating flows to deliver goods, thus reducing the positive effects of applying this concept (Sampaio et al., 2019; Paloheimo et al., 2016).

\section{Conclusion}

Unused capacities of logistics subsystems, territorial dispersion and numerous flows that households generate, make they potentially very important providers of logistics services, such as delivery, storage and waste collection. These services have been provided by households in the past, but their more intensive development and mass realization as a crowd service have been encouraged by the development of information and communication technologies, social networks and mobile applications. These technologies, networks and applications are platforms for connecting providers (households) and users of crowd logistics services (individuals/households, companies) in a wider geographical area. Crowd services have a special significance for the last mile of the supply chain, i.e. home delivery. Services can be performed in the complete last mile or some of its segments.

In this paper, the role of households in the performing of logistics flows of other households and companies is analyzed, structuring and analysis of basic household crowd logistics services are performed and basic benefits, as well as disadvantages, problems and challenges in applying the crowd logistics concept are identified. Special attention is paid to crowd services in the last mile of the supply chain. Also, the paper describes the collection of waste by households, which has not been considered as a crowd service in previous research. A comprehensive analysis of household crowd logistics services achieved the basic goal and contribution of the paper.

Given that there are numerous economic, environmental and social benefits of applying the crowd logistics concept, both in urban and 
rural areas, it is necessary to explore the role of crowd services in affirming and implementing the concept of sustainability in logistics in these areas. Also, since most of the research so far deals with the commercial aspect of the application of crowd logistics, it is necessary to analyze the possibilities of developing nonprofit, humanitarian crowd logistics, which can also be very important, especially in the social context. Inevitably, attention should be paid to the technologies used in crowd logistics. Using households as CDPs, the models for selecting households to perform this function should also be the focus of researchers' attention. Finally, a comparative analysis of crowd logistics services and the services of professional logistics providers in home delivery should also be the subject of future research.

\section{Acknowledgements}

This paper was supported by the Ministry of Education, Science and Technological Development of the Republic of Serbia (projects TR36006 and TR36027).

\section{References}

Agatz, N.; Erera, A.; Savelsbergh, M., Wang, X. 2012. Optimization for dynamic ridesharing: A review, European Journal of Operational Research 223(2): 295 - 303.

Aslant, A.M.; Agate, N.; Kroon, L.; Zuidwijk, R. 2018. Crowdsourced Delivery - A Dynamic Pickup and Delivery Problem with Ad Hoc Drivers, Transportation Science 53(1): 1-14.

Cairns, S. 1996. Delivering alternatives, Transport Policy 3(4): 155-176.

Carbone, V.; Roquet, A.; Roussat, C. 2017. The Rise of Crowd Logistics: A New Way to Co-Create Logistics Value, Journal of Business Logistics 38(4): 238-252.
Devari, A.; Nikolaev, A. G.; He, Q. 2017. Crowdsourcing the last mile delivery of online orders by exploiting the social networks of retail store customers, Transportation Research Part E: Logistics and Transportation Review 105: 105-122.

Frehe, V.; Mehmann, J.; Teuteberg, F. 2017. Understanding and assessing crowd logistics business models - using everyday people for last mile delivery, Journal of Business \& Industrial Marketing 32(1): 75-97.

Ghajargar, M.; Zenezini, G.; Montanaro, T. 2016. Home delivery services: innovations and emerging needs, IFAC-PapersOnLine 49(12): 1371-1376.

Howe, J. 2006. The Rise of Crowdsourcing. Available from Internet: <http://www.wired.com/wired/ archive/14.06/crowds.html>.

Hübner, A.; Kuhn, H.; Wollenburg, J. 2016. Last mile fulfilment and distribution in omni-channel grocery retailing, International Journal of Retail \& Distribution Management 44(3): 228-247.

Joerss, M.; Schroder, J.; Neuhaus, F.; Klink, C.; Mann, F. 2016. Parcel delivery: the future of last mile. In: McKinsey\&Company (Travel, Transport and Logistics), 1-32.

Klumpp, M. 2017. Crowdsourcing in Logistics: An Evaluation Scheme, In Freitag, M.; Kotzab, H.; Pannek, J. (Ed.), Dynamics in Logistics, Proceedings of the 5th International Conference LDIC, Bremen, 401-411.

McKinnon, A. C.; Tallam, D. 2003. Unattended delivery to the home: an assessment of the security implications, International Journal of Retail \& Distribution Management 31(1): 30-41.

Mehmann, J.; Frehe, V.; Teuteberg, F. 2015. Crowd Logistics - A Literature Review and Maturity Model, In Proceedings of the Hamburg International Conference of Logistics (HICL), Hamburg, 117-145. 
Mladenow, A.; Bauer, C.; Strauss, C. 2015. Crowdsourcing in logistics, In Proceedings of the 17th International Conference on Information Integration and WebBased Applications \& Services - iiWAS '15, Brussels, 244-251.

Mladenow, A.; Bauer, C.; Strauss, C. 2016. Crowd logistics: the contribution of social crowds in logistics activities, International Journal of Web Information Systems 12(3): 379-396.

Paloheimo, H.; Lettenmeier, M.; Waris, H. 2016. Transport reduction by crowdsourced deliveries - a library case in Finland, Journal of Cleaner Production 132: 240 - 251.

Piplani, R.; Saraswat, A. 2012. Robust optimisation approach to the design of service networks for reverse logistics, International Journal of Production Research 50(5): 1424-1437.

Rai, H.B.; Verlinde, S.; Merckx, J.; Macharis, C. 2017. Crowd logistics: an opportunity for more sustainable urban freight transport? European Transport Research Review 9(39): 1-13.

Rougès, J.; Montreuil, B. 2014. Crowdsourcing delivery: new interconnected business models to reinvent delivery. In Proceedings of the 1st International Physical Internet Conference, Quebec City, 1-19.

Rześny-Cieplińska, J.; Szmelter-Jarosz, A. 2019. Assessment of the Crowd Logistics Solutions-The Stakeholders' Analysis Approach, Sustainability 11(19): 5361 .

Sampaio, A.; Savelsbergh, M.; Veelenturf, L.; Van Woensel, T. 2019. Crowd-Based City Logistics, In Sustainable Transportation and Smart Logistics, 381-400.

Subedi, M. 2018. Smart Approach to Warehousing: Self-storage Industry. Bachelor's Degree Thesis,Yrkeshögskolan Arcada, Helsinki. 43p.

Tadić, S.; Veljović, M. 2020a. Logistics flows of household, Tehnika 75(2): 225-237.
Tadić, S.; Veljović, M. 2020b. Logistics of rural tourism, International journal for traffic and transport engineering IJTTE 10(3): 323-350.

Tadić, S.; Veljović, M. 2020c. Household logistics in tourism supply chain. In: Bevanda, V., Štetić, S. (eds.), 5th International Thematic Monograph: Modern Management Tools and Economy of Tourism Sector in Present Era, Association of Economists and Managers of the Balkans - UDEKOM Balkan (Belgrade, Serbia) in cooperation with the Faculty of Tourism and Hospitality (Ohrid, North Macedonia), 67-80.

Tadić, S.; Veljović, M. 2020d. Home delivery: concept and characteristics, International journal for traffic and transport engineering - IJTTE 10(4): 519 - 533.

Tadić, S.; Veljović, M. 2020e. Return flows in home delivery. In Proceedings of the 19 th International Conference on Transport Science (ICTS), Portoroz, 348-354.

Tadić, S.; Veljović, M. 2021. Home delivery: a framework for structuring, International journal for traffic and transport engineering-IJTTE 11(1): 30 - 74.

Tadić, S.; Zečević, S. 2016. Modeling of city logistics concepts [In Serbian: Modeliranje koncepcija city logistike]. University of Belgrade, Faculty of Transport and Traffic Engineering, Belgrade, Serbia. 358 p.

Visser, J.; Nemoto, T.; Browne, M. 2014. Home Delivery and the Impacts on Urban Freight Transport: A Review, Procedia-Social and Behavioral Sciences 125: 15-27.

Wang, Y.; Zhang, D.; Liu, Q.; Shen, F.; Lee, L. H. 2016. Towards enhancing the last-mile delivery: An effective crowd-tasking model with scalable solutions, Transportation Research Part E: Logistics and Transportation Review 93: 279-293.

Yuen, K. F.; Wang, X.; Ng, L. T. W.; Wong, Y. D. 2018. An investigation of customers' intention to use selfcollection services for last-mile delivery, Transport Policy 66: 1-8. 